\title{
Impactos sociais e econômicos da COVID-19
}

Samilly Silva Miranda, ${ }^{1}$ Jane Mary de Medeiros Guimarães, ${ }^{2}$ José Rivaldo França, ${ }^{3}$ Marcos Pereira, ${ }^{4}$ Diana Lima dos Santos, ${ }^{5}$ Kionna Oliveira Bernardes Santos, ${ }^{6}$ Fernanda Borges Serpa, ${ }^{7}$ Antonio José Costa Cardoso, ${ }^{8}$ Marcio Santos da Natividade, ${ }^{9}$ Carlos Okey-Reis, ${ }^{10}$ Francisco Funcia, ${ }^{11}$ Erika Santos de Aragão ${ }^{12}$

1 Doutorado em Saúde Coletiva. Professora adjunta do Instituto de Saúde Coletiva (ISC) da Universidade Federal da Bahia (UFBA).

2 Substituir por: Doutorado em Saúde Pública. Professora Adjunta do Instituto de Humanidades, Artes e Ciências da Universidade Federal do Sul da Bahia (UFSB).

3 Doutorado em Saúde Pública. Pós-doutorando em Saúde Coletiva pelo Centro de Integração de Dados e Conhecimentos para Saúde (Cidacs) da Fundação Oswald Cruz (Fiocruz) da Bahia.

4 Doutorado em Saúde Pública. Professor Adjunto do Instituto de Saúde Coletiva (ISC) da Universidade Federal da Bahia (UFBA).

5 Economista, mestrado em Saúde Coletiva. Coordenadora na Secretaria de Ciência e Tecnologia da Bahia (SECTI).

6 Doutorado em Saúde Coletiva. Professora Adjunta da Faculdade de Medicina da Universidade Federal da Bahia (UFBA).

7 Especialização em Análise de Dados em Políticas Públicas. Membro da equipe técnica da Secretaria de Ciência, Tecnologia e Insumos Estratégicos do Ministério da Saúde.

8 Doutorado em Saúde Pública. Professor Adjunto do Instituto de Saúde Coletiva (ISC) da Universidade Federal da Bahia (UFBA).

9 Doutorado em Saúde Pública. Professor Adjunto do Instituto de Saúde Coletiva (ISC) da Universidade Federal da Bahia (UFBA).

10 Economista, doutor em Saúde Coletiva pelo Instituto de Medicina Social (IMS) da Universidade do Estado do Rio de Janeiro (UERJ) e pós-doutor pela Yale School of Management (New Haven, EUA). Técnico de Planejamento e Pesquisa do Instituto de Pesquisa Econômica Aplicada (IPEA).

11 Mestrado em Economia Política. Professor da Universidade de São Caetano do Sul (USCS) e Consultor técnico da Comissão de Orçamento e Financiamento (Cofin) do Conselho Nacional de Saúde (CNS).

12 Doutorado em Saúde Pública. Professor Adjunto do Instituto de Saúde Coletiva (ISC) da Universidade Federal da Bahia (UFBA)

MIRANDA, S. S.; GUIMARÃES, J. M. de M.; FRANÇA, J. R.; PEREIRA, M.; SANTOS, D. L. dos.; OLIVEIRA, K. B. S.; SERPA, F. B.; CARDOSO, A. J. C.; NATIVIDADE, M. dos S.; OKEY-REIS, C.; FUNCIA, F.; ARAGÃO, E. S. de. Impactos sociais e econômicos da COVID-19. In: BARRETO, M. L.; PINTO JUNIOR, E. P.; ARAGÃO, E.; BARRAL-NETTO, M. (org.). Construção de conhecimento no curso da pandemia de COVID-19: aspectos biomédicos, clínico-assistenciais, epidemiológicos e sociais. Salvador: Edufba, 


\section{Introdução}

Em decorrência da crise humanitária da COVID-19 e da necessidade de fortalecer a agenda de discussão sobre os impactos sociais e econômicos inerentes à pandemia, este capítulo visa discutir as estratégias de mitigação dos efeitos econômicos e sociais adotadas no Brasil.

Muito se tem debatido sobre as possibilidades de retorno das atividades econômicas, no entanto, flexibilizar as medidas de distanciamento sem a existência de terapias efetivas ou acesso ampliado às vacinas específicas para o controle da doença, além de colocar em risco vidas humanas, desencadeará um colapso no sistema de saúde.

$\mathrm{Na}$ tentativa de minimizar os danos inerentes a esta pandemia, algumas estratégias econômicas foram adotadas no Brasil. Embora a extensão futura dos impactos sociais e econômicos não seja previsível, é fundamental discutir as medidas adotadas para o enfrentamento da crise e suas possíveis repercussões a médio e longo prazo.

A análise crítica conduzida ao longo do texto buscará refletir principalmente as ações desenvolvidas para grupos em situação de vulnerabilidade social. A pandemia se interioriza no país, escancarando as 
iniquidades sociais e as diferenças econômicas entre as classes. As pessoas em situação de pobreza, ou com algum tipo de insegurança financeira, são aquelas que estão na informalidade, e que na maioria das vezes precisam sair de casa para garantir seu sustento; são aquelas que residem em moradias superlotadas, locais altamente suscetíveis à infecção por COVID-19. Logo, a governança de enfrentamento deve ser uma gestão reativa e corretiva que vise à redução de riscos, não se restringindo apenas às ações do setor saúde.

\section{Economia e impacto na vulnerabilidade social}

A relação entre desigualdade e saúde encontra-se presente no cotidiano das populações marginalizadas de todo o mundo, mesmo antes da ocorrência da pandemia de SARS-CoV-2. Entretanto, na ocorrência da COVID-19, uma parcela expressiva da população tem sido lançada à condição da extrema pobreza, fruto da interação entre o reflexo histórico da desigualdade estrutural, social e econômica, do expressivo contingente de trabalhadores informais ou desempregados, potencializada pelas precárias condições, por exemplo, do sistema de produção e comercialização de alimentos, que envolvem sistemas econômicos e de agronegócios. (BALTRUSIS; D’OTTAVIANO, 2009; POWER et al., 2020) Dessa forma, crises sanitárias afetam a dinâmica espacial e são capazes de produzir inseguranças em diferentes esferas: biológica, política, econômica e social. (CÂMARA et al., 2020)

Para compreender o impacto da COVID-19 na vulnerabilidade social, inicialmente, é preciso desconstruir a figura de doença e/ou crise sanitária democrática, vinculada em alguns meios de comunicação. O pressuposto da desvantagem social perpassa desde as formas de controle, acesso ao diagnóstico, tratamento, 
até as condições de sobrevivência e retomada de desenvolvimento humano. (CALMON, 2020) Assim, parte-se do conceito de que a relação entre os efeitos da pandemia em um contexto de vulnerabilidade social já foi constatada em crises sanitárias anteriores. O olhar do passado revela que desigualdades sociais preexistentes determinam, em algum grau, o fluxo de transmissão e as estratégias de enfrentamento dos países. (PIRES, 2020)

$\mathrm{O}$ impacto da pandemia do coronavírus no setor produtivo representa uma ruptura estrutural com o nível de desenvolvimento econômico e social até então estabelecido como meta no contexto mundial. O Fundo Monetário Internacional (FMI) denominou o efeito da pandemia como "pior crise econômica desde a Grande Depressão” de 1929. Em parte, isso se deve ao efeito das medidas restritivas recomendadas pela Organização Mundial de Saúde (OMS) e adotadas pela maioria dos países, como estratégia de contingenciamento fundamental, pela alta transmissibilidade do SARS-CoV-2. Inclusive, um estudo realizado por 43 cidades americanas mostra que as cidades que adotaram medidas restritivas precocemente tiveram retomada mais rápida do crescimento econômico pós-pandemia. (CORREIA; LUCK; VERNER, 2020)

Dados da Organização Internacional do Trabalho (OIT) sugerem que cerca de $81 \%$ da força de trabalho mundial encontra-se em países que passaram ou retornaram à adoção de medidas de contingenciamento de forma obrigatória ou recomendada. Ainda que subestimado no início da crise provocada pela pandemia, o efeito esperado a curto e médio prazo sugeriu a perda de cerca de 25 milhões de empregos, situação que ultrapassa os níveis de desemprego provocados pela crise de 2007-2008. (ILO, 2020) Além, da perda de postos de trabalho estima-se, globalmente, uma perda na renda do trabalhador, especialmente para aqueles desprotegidos e com trabalho informal. (ILO, 2020) 
Entretanto, o efeito da crise encontrou diferentes cenários com desigualdades e iniquidades estruturais entre os países. De maneira geral, países com economia sólida garantiram incentivos fiscais e protegeram, de certa forma, os níveis de emprego e renda da população. Em países com economias emergentes, como os da América Latina, as medidas restritivas e consequente proteção social foram insuficientes, pelas condições de desigualdades estruturais e atingiram de forma diferenciada a população. Nas famílias de baixa renda - abaixo do quintil de distribuição de renda -, após um mês de medidas restritivas, 65\% das famílias tiveram, ao menos, uma perda de emprego entre um dos membros. Esse percentual cai para $22 \%$ nas famílias com renda mais elevada. (BUSSO; MESSINA, 2020)

A OIT aponta disparidade existente nos estímulos à retomada de desenvolvimento econômico/social entre os países. Naqueles de baixa renda, o volume das ações de incentivo se aproxima de $1 \%$ do valor total dos programas de incentivos fiscais, entre os países considerados com economia sólida. Ao analisar o déficit de proteção social já existente entre esses países e a limitação de recursos para mitigação da crise do mercado de trabalho, amplia-se a possibilidade de aprofundamento da crise vivenciada e a manutenção de uma grande parcela da população desprotegida, com ameaça à sobrevivência e ao retorno do desenvolvimento social.

Dessa forma, o agravamento da pobreza em diferentes populações no contexto pandêmico pode ser intensificado de acordo com os determinantes sociais da saúde preexistentes e as repercussões das políticas sociais, condições de vida no âmbito comunitário e individual de populações indígenas, quilombolas, negra e LGBTQI+, em especial nos países pobres onde a pandemia exibe o lado mais perverso da crise na saúde. (PEREIRA; OLIVEIRA, 2020)

Por outro lado, é importante destacar o aprofundamento das desigualdades sociais em benefício de grupos mais ricos: 
multimilionários e grupos com alto poder econômico estão usando a pandemia como uma oportunidade de obter lucros exorbitantes com produtos e serviços. (LABORDE et al., 2020; SANDERS, 2020) Em vez de permitir que multimilionários se tornem muito mais ricos, os governos precisam defender as famílias trabalhadoras. Nesse sentido, sugere-se que os Estados possam taxar os enormes ganhos que os bilionários obtiveram durante a pandemia e usar esse dinheiro para garantir cuidados de saúde e alimentação de pessoas e famílias em contexto de pobreza. (SANDERS, 2020) Assim, entende-se que o Estado deve assumir responsabilidade política, social e econômica que lhe é atribuída, em todos os níveis da gestão - municipal, estadual e federal -, com vistas à redução de iniquidades. (PEREIRA; OLIVEIRA, 2020)

\section{Medidas econômicas adotadas no Brasil}

No Brasil, a primeira lei que dispõe sobre as medidas para enfrentamento da emergência de saúde pública decorrente do coronavírus foi aprovada em 6 de fevereiro de 2020 (Lei $\mathrm{n}^{\circ}$ 13.979). Considerou-se principalmente medidas coletivas de proteção isolamento, quarentena, restrição excepcional e temporária de entrada e saída do país - e estratégias que facilitassem a aquisição de bens, serviços e insumos de saúde destinados ao enfrentamento da doença.

À medida que a doença foi se disseminando pelo país, ampliou-se a necessidade de fortalecer as estratégias não farmacológicas para reduzir a taxa de contaminação e minimizar um possível colapso no sistema de saúde. Esse cenário desencadeou efeitos na oferta e na demanda dos serviços, pela redução natural do consumo das famílias e pelas restrições no comércio, nos transportes e nas empresas que não se enquadraram nos 
serviços essenciais. Como consequência, houve redução da renda de muitas das famílias, aumento do desemprego e queda do faturamento das empresas. (SILVA, 2020)

Esse ambiente de grandes incertezas requereu do governo federal a criação de políticas econômicas que buscassem minimizar os efeitos danosos dos choques econômicos causados pelo coronavírus. As principais medidas adotadas envolveram investimentos emergenciais na saúde; proteção econômica à população mais vulnerável; garantia de sobrevivência das empresas e de manutenção do emprego (Quadro 1). 
Quadro 1 - Principais medidas adotadas para o combate aos efeitos econômicos da COVID-19 no Brasil

\begin{tabular}{|c|c|c|c|}
\hline \multirow[b]{2}{*}{ MEDIDAS ADOTADAS } & \multicolumn{3}{|c|}{ OBJETIVO DA MEDIDA } \\
\hline & $\begin{array}{l}\text { Manutenção } \\
\text { do emprego }\end{array}$ & $\begin{array}{l}\text { Auxilio às } \\
\text { famílias }\end{array}$ & $\begin{array}{l}\text { Proteção } \\
\text { das } \\
\text { empresas }\end{array}$ \\
\hline $\begin{array}{l}\text { Possibilidade de redução da carga de trabalho em } 25 \% \text {, } \\
\qquad 50 \% \text { ou } 70 \%\end{array}$ & $\mathrm{x}$ & & $x$ \\
\hline $\begin{array}{l}\text { Normatização sobre o teletrabalho, férias e bancos de } \\
\text { horas }\end{array}$ & $\mathrm{x}$ & & $x$ \\
\hline $\begin{array}{l}\text { Saque emergencial do FGTS de até } \mathrm{R} \$ 1.045,00 \text { por } \\
\text { cotista }\end{array}$ & $\mathrm{x}$ & $\mathrm{x}$ & \\
\hline Auxílio emergencial de $\mathrm{R} \$ 600$ & & $\mathrm{x}$ & \\
\hline Zerar a alíquota do IOF de crédito & $\mathrm{x}$ & $\mathrm{x}$ & $\mathrm{x}$ \\
\hline $\begin{array}{l}\text { Crédito para pagamento da folha salarial de pequenas e } \\
\text { médias empresas }\end{array}$ & $\mathrm{x}$ & & $x$ \\
\hline Adiamento das parcelas do financiamento imobiliário & & $x$ & \\
\hline $\begin{array}{c}\text { Antecipação do pagamento do } 13^{\circ} \text { salário para } \\
\text { beneficiários do INSS }\end{array}$ & & $x$ & \\
\hline Ampliação do número de beneficiários no Bolsa Família & & $x$ & \\
\hline Pagamento da conta de luz da população de baixa renda & & $\mathrm{x}$ & \\
\hline Pausa no reajuste do preço de remédios & & $\mathrm{X}$ & \\
\hline Antecipação de um salário-mínimo para auxílio-doença & & $\mathrm{x}$ & \\
\hline $\begin{array}{c}\text { Suspensão, por } 120 \text { dias, da exigência de } \\
\text { recadastramento anual para comprovação de vida dos } \\
\text { beneficiários do INSS }\end{array}$ & & $\mathrm{x}$ & \\
\hline $\begin{array}{c}\text { Crédito do BNDES para empresas com um volume de } \\
\text { empréstimos de } 0,6 \% \text { do PIB }\end{array}$ & & & $x$ \\
\hline $\begin{array}{l}\text { Prorrogação do prazo de apresentação da declaração de } \\
\text { alguns tributos federais (como a declaração do Imposto } \\
\text { de Renda) }\end{array}$ & & $\mathrm{x}$ & $x$ \\
\hline $\begin{array}{l}\text { Imposto sobre Operações Financeiras sobre as operações } \\
\text { de crédito contratadas no período entre 03/04/20 a } \\
\text { 03/07/20 foi reduzido a zero }\end{array}$ & & & $\mathrm{x}$ \\
\hline
\end{tabular}

Fonte: adaptado de Brasil (2020i). 
A partir de uma análise crítica, pode-se inferir que as estratégias criadas pelo governo, na tentativa de garantir a manutenção do emprego e renda, têm pontos positivos e negativos. A Medida Provisória (MP) n 936/2020, por exemplo, embora o objetivo seja preservar os vínculos trabalhistas formais e garantir a renda dos trabalhadores, tem sido questionada quanto aos grupos pela qual a medida tende a beneficiar e o impacto no rendimento total mensal do trabalhador, caso haja adesão ao programa. Ao analisar aqueles que recebem até três salários-mínimos, a reposição pode ser de 70\%, em caso de redução da jornada, ou até $58 \%$, em situações de suspensão da jornada. As perdas são maiores quanto maior o salário e quanto maior for o corte da jornada. (COSTA; REIS, 2020; TROVÃO, 2020) Em 6 de julho de 2020, essa medida foi convertida na Lei $\mathrm{n}^{\circ} 14.020$, que da mesma maneira poderá trazer prejuízos na renda de muitos trabalhadores. (SILVA, 2020)

A MP $n^{\circ} 927 / 2020$ dispõe sobre normas para teletrabalho, antecipação de férias individuais, concessão de férias coletivas, aproveitamento e antecipação de feriados, banco de horas, suspensão de exigências administrativas em segurança e saúde no trabalho, diferimento do recolhimento do Fundo de Garantia do Tempo de Serviço (FGTS) e suspensão dos contratos de trabalho para qualificação (o que foi objeto de muitas críticas). Apesar de ter tido seu prazo de vigência encerrado no dia 19 de julho de 2020, trouxe algumas reflexões importantes na seara da economia e do trabalho. O teletrabalho possibilita às empresas manterem seus rendimentos e evitarem a falência, assim como garantir o emprego de muitos trabalhadores em que suas funções são passíveis de serem realizadas em casa. No entanto, o trabalhador pode cumprir jornadas com cargas horárias excessivas e não receber hora extra e adicional noturno. (SANTOS; MIRANDA; MONTI JUNIOR, 2020) 
Quanto ao auxílio emergencial, ao mesmo tempo que se considera que este possui maior efeito de atenuação sobre o impacto negativo da perda dos trabalhos (KOMATSU; MENEZES-FILHO, 2020), se questiona sobre sua capacidade de atingir aqueles que realmente necessitam, bem como se a renda disponibilizada é capaz de garantir as necessidades cotidianas das famílias brasileiras. (BRANDÃO, 2020) Para o Instituto de Pesquisa Econômica Aplicada (IPEA), a partir de um estudo realizado com microdados da Pesquisa Nacional por Amostra de Domicílio (PNAD) COVID-19 de julho, o auxílio emergencial foi suficiente para superar em $16 \%$ a perda da massa salarial entre os que permaneceram ocupados, em relação ao mês anterior. Acrescentaram que 6,5\% dos domicílios - cerca de 4,4 milhões - sobreviveram apenas com os rendimentos recebidos desse auxílio. (CARVALHO, 2020)

As medidas governamentais tomadas para a proteção das famílias envolveram medidas previdenciárias, fiscais e tributárias, incidindo sobre despesas regulares como financiamento imobiliário e consumo de energia elétrica. A fim de reduzir o impacto sentido pelas famílias durante a pandemia, especialmente pela redução da renda mensal, essas MPs envolveram várias pastas do governo federal.

Inicialmente, a MP nº 933/20, de 31 de março de 2020, suspendeu pelo prazo de 60 dias, o ajuste anual de preços de medicamentos para o ano de 2020 como uma das estratégias para a redução dos impactos desses itens na renda familiar durante a pandemia. Em adição, o Decreto ${ }^{\circ} 10.305$, de $1^{\circ}$ de abril de 2020 , zerou as alíquotas de Imposto sobre Operações Financeiras (IOF) sobre as operações de crédito, independente da sua finalidade. Sobre os créditos pessoais, incidiram ainda ampliação dos prazos para pagamento de créditos consignados e redução das taxas de juros. O pagamento do Imposto de Renda da Pessoa Física (IRPF) 
também teve seu prazo estendido por 60 dias para entrega da declaração.

À semelhança dos benefícios concedidos pela MP n ${ }^{\circ}$ 936/2020, de $1^{\circ}$ de abril de 2020, que instituiu o Programa Emergencial de Manutenção do Emprego e da Renda e dispõe sobre medidas trabalhistas complementares para enfrentamento do estado de calamidade pública, a Lei $\mathrm{n}^{\circ}$ 13.982, sancionada em 2 de abril de 2020, estabelece regras para a concessão de benefícios de prestação continuada ou previdenciários ou auxílio emergencial para famílias com renda comprometida em consequência das medidas de proteção individual, restringindo a circulação das pessoas, e de proteção para a sobrevivência das empresas, que flexibilizaram os contratos, permitindo a redução de jornadas ou suspensão dos contratos temporariamente, e consequentemente, os salários. Avaliando a situação particular de cada família e com base na renda comprometida durante o estado de calamidade pela pandemia, a lei permite a acumulação de mais um benefício para famílias com portadores de deficiência ou idosos.

Em 9 de abril de 2020, a Caixa Econômica Federal anunciou uma pausa de 90 dias para o pagamento das prestações de crédito imobiliário, ou redução do valor mensal por igual período para os clientes adimplentes. Para os inadimplentes, a renegociação dos créditos foi autorizada, com redução ou suspensão temporária dos pagamentos de parcelas. Para os contratos novos, a carência foi ampliada para até 180 dias. Por sua vez, duas parcelas seriam liberadas, sem a obrigatoriedade da vistoria, para os financiamentos de material de construção.

A MP ${ }^{\circ} 950 / 20$, de 8 de abril de 2020, isenta os consumidores beneficiários da Tarifa Social de Energia Elétrica (TSEE) do pagamento da conta de luz entre $1^{\circ}$ de abril a 30 de junho de 2020. Outras medidas previdenciárias incluem a antecipação de um salário-mínimo mensal por até três meses, condicionada à 
apresentação de atestado médico e cumprimento do período de carência do benefício, e a suspensão da necessidade da "prova de vida” aos aposentados por 120 dias. Já para os maiores de 18 anos, sem enquadramento em outros benefícios previdenciários e sem vínculos ativos, é permitida a acumulação de até dois auxílios emergenciais por família cuja renda per capita mensal seja limitada a 1/2 salário-mínimo ou três salários-mínimos de renda familiar total mensal.

De maneira geral, apesar de todas as medidas buscarem minimizar os impactos no emprego e na renda, e como via de consequência na economia, infelizmente as decisões de política econômica ainda se deparam com grandes incertezas em relação à extensão, abrangência e intensidade das crises da economia brasileira e da economia internacional. (SILVA, 2020) Além das medidas terem sido insuficientes para manter o consumo das famílias e o desemprego em massa, estão sujeitas a perspectiva da volta a submissão à regra de ouro e ao teto de gasto da Emenda Constitucional (EC) $n^{\circ}$ 95/2016. Nesse sentido, a retomada da economia é um desafio a ser superado. É crucial refletir não apenas quanto ao volume de recursos a serem alocados nas diferentes iniciativas e quanto ao tempo que os estímulos fiscais e monetários devem ser implementados. É preciso considerar ainda a necessidade de salvar vidas, por meio do financiamento adicional em saúde pública, sem considerar a opção de trocar as medidas relacionadas ao financiamento da saúde pública por aquelas que visem sanar danos econômicos. Será necessário, portanto, criar e/ ou fortalecer estratégias que busquem incentivar a retomada dos investimentos e do crescimento econômico orientado à inclusão e ao bem-estar social. 


\section{Brasil pós-GOVID-19}

As projeções de políticas públicas pós-COVID-19 são bastante incertas, visto que, mesmo em países onde a pandemia foi controlada há alguns meses, tem sido observado um aumento nas taxas de contaminação, internamento e mortalidade decorrentes do vírus. (ALTIG et al., 2020; BAQAEE et al., 2020) Isso implica dizer que as políticas públicas estão constantemente sendo atualizadas para dar respostas a cenários dinâmicos. Nesse sentido, é estratégico monitorar e analisar o que os diversos países têm feito, no âmbito das políticas públicas, para contornar os efeitos econômicos negativos, ao passo em que conseguem condições toleráveis de controle da pandemia.

Em relação a medidas sanitárias, há relativo consenso, neste cenário e possivelmente nos próximos anos, sobre a importância do uso combinado de medidas de proteção eficazes, que incluem uso de máscaras, limites no tamanho das atividades em grupo, especialmente em ambientes fechados, distanciamento social, aumento das taxas de testes e quarentena, especialmente para idosos. (BAQAEE et al., 2020) Pelo menos enquanto não estejam disponibilizadas vacinas para toda a população, o que irá requerer esforço científico, logístico e econômico por parte dos países.

No que concerne às medidas econômicas específicas, economistas têm argumentado, como se observa no estudo de Alves e Kvangraven (2020), que a ausência de uma análise social ampla, associada à adoção de políticas econômicas baseadas no paradigma econômico dominante - o fundamentalismo de mercado -, de um modo geral, ampliam fragilidades do estado e desigualdades sociais. Essa pandemia, como outras crises, mostrou que o mercado não dá conta do enfrentamento da mesma. Tampouco é capaz de minimizar as desigualdades que se desvelam e intensificam. Ao contrário, durante a pandemia da COVID-19, a soma 
das riquezas dos bilionários no mundo superou pela primeira vez a marca dos US\$ 10 trilhões. Segundo pesquisa divulgada em outubro de 2020, entre abril e julho, os bilionários dos setores industrial, de tecnologia e de saúde foram os que tiveram o maior aumento na sua riqueza, com saltos de respectivamente $44 \%, 41 \%$ e 36\%. (CHADE, 2020) No Brasil, o número de bilionários também aumentou, ao passo que o desemprego bateu recordes históricos.

Por isso, os chamados economistas heterodoxos, que se baseiam em ações alternativas do comportamento humano como crítica aos agentes otimizadores racionais e do individualismo metodológico da corrente dominante, têm criticado a manutenção de estratégias como a redução do papel do estado e a chamada austeridade fiscal, focada sobretudo na redução de gasto público. Tem sido destacada a adoção de perspectivas de economistas feministas, que apontam para a importância de compreender a reprodução social e as relações sociais entre os atores. (ALVES; KVANGRAVEN, 2020; BOHOSLAVSKY; RULLI, 2020; ONU MUJERES; CEPAL, 2020) Há também mais espaço, neste campo, para explorar as desigualdades relacionadas a categorias sociais agregadas, como gênero, classe e raça, já que há uma ampliação das desigualdades existentes entre estes subgrupos. (AHMED et al., 2020; NASSIF-PIRES, 2020; VAN DORN; COONEY; SABIN, 2020) Em outras palavras, os economistas heterodoxos identificam e analisam as forças estruturais que estão por trás das tendências polarizadoras da economia global.

Seguindo essa perspectiva, é consenso que uma atuação maior do Estado se faz urgente e necessária para o enfrentamento da crise. Assim, mesmo estudos publicados por organismos marcados por propostas "neoliberais" como o Banco Mundial, e FMI, apontam que o mundo terá uma das piores crises econômicas das últimas décadas. O Banco Mundial prevê retração de 5,2\% do Produto Interno Bruto (PIB) global e o FMI, 3\%, sendo que América 
Latina e Caribe estão entre as regiões mais impactadas com a desaceleração, que se estima será muito superior à média mundial. O Banco Mundial calcula que o número de pessoas que vive em extrema pobreza com apenas US\$ 1,90 por dia irá atingir 150 milhões de pessoas até 2021, sendo que oito em cada dez novos pobres estarão em países de renda média, como o Brasil. (GUIMÓN, 2020; THE WORLD BANK, c2020)

Em decorrência das previsões de retração econômica, associada ao aumento da pobreza e desigualdade, tais organismos destacam a necessidade de adoção de políticas focadas em amortecer as consequências dessa crise, que pode ser a maior desde a crise da década de 1930. Assim, as políticas fiscais devem ir ao caminho oposto ao que o Brasil tem adotado, com maior participação do Estado para proteger as populações vulneráveis, ampliar a geração de emprego, de um lado, e aumento da arrecadação focado na tributação dos mais ricos, taxação de grandes fortunas, dentre outras medidas.

Mesma direção é apontada pela Comissão Econômica para América Latina e Caribe (CEPAL, 2020), que sugere que os Estados devem adotar um conjunto de políticas fiscal e monetária capaz de fortalecer os sistemas de proteção social, de modo a proteger os setores mais vulneráveis e a classe média, por meio de transferências diretas, seguro-desemprego, benefícios a trabalhadores subempregados e por conta própria. Ao mesmo tempo que deve preservar a capacidade produtiva e criar condições para a reativação da atividade econômica, por meio de mecanismos de liquidez para as empresas, especialmente as pequenas e médias. Como política monetária, é recomendada a busca por estabilidade nas taxas de câmbio, por meio de intervenção do banco central nos mercados de moeda; manter a solvência e o funcionamento adequado do sistema bancário, garantindo que os bancos 
comercializem a níveis adequados de liquidez e permitam adiar pagamentos de dívidas para empresas e famílias.

A despeito de diversos países, inclusive o Brasil, terem adotado uma agenda neoliberal para enfrentar os efeitos econômicos pós-pandemia, têm sido observadas, em outros países, estratégias de retomada econômica que visem tais aspectos humanitários. No estudo de McKee e Stuckler (2020), os pesquisadores sugerem uma mudança política focada na austeridade dos gastos do Estado, atualmente predominante no cenário mundial, para uma participação estatal mais solidária e apartada da ideia de riqueza da nação. Menciona a importância de o Estado oferecer sistema de saúde gratuito e universal e proteção de renda aos trabalhadores.

Alguns países da Europa, como Inglaterra, França, Alemanha, Holanda, Portugal, Suécia, Espanha e Suíça, adotaram formas diferentes para o que chamam de Job Retention Scheme (JRS) ou esquema de retenção de emprego, no qual os empregadores são subsidiados pelo Estado para manter os trabalhadores vinculados aos seus empregadores. (MAYHEW; ANAND, 2020) Assim, buscam evitar demissões em grande escala e os problemas subsequentes de muitas pessoas desempregadas, e sem caminhos para um novo trabalho. As medidas variaram entre liberação temporária do empregado - mantendo o vínculo -, licença, trabalho de curta duração subsidiado, dentre outras formas. Contudo, os autores questionam a viabilidade de longo prazo desse esquema ou mesmo quantos empregadores, de fato, farão isso em um cenário incerto quanto ao fim absoluto da pandemia. Os instrumentos políticos cruciais vão depender da capacidade de controlar a transmissão por distanciamento social e rastrear a população em escala. (MAYHEW; ANAND, 2020)

Além dessas medidas, o estudo de McKee e Stuckler (2020) alerta sobre a importância de proteção econômica das empresas, especialmente das pequenas empresas, por meio de, por exemplo, 
empréstimos sem juros, permissão de atraso no pagamento de impostos, e outros encargos. $\mathrm{O}$ estudo também reforça que o Estado precisa, adicionalmente, atuar inibindo a ação de agentes exploradores da crise, por meio de controles governamentais sobe os preços - inibindo aumentos substanciais e abusivos nos preços e nas taxas de juros.

\section{Efeitos socioeconômicos da COVID-19 no Brasil: o retorno à austeridade fiscal}

Como destacado, em curto e médio prazo, as perspectivas para a sustentabilidade das medidas socioeconômicas adotadas para mitigar os efeitos da pandemia causada pelo coronavírus dependem de decisões políticas de difícil assimilação e prospeç̧ão, uma vez que dentro do próprio governo não está bem definida a linha de atuação da política econômica que será adotada para a conjuntura gerada pela crise sanitária. Essa dubiedade se expressa, no Brasil, nas contradições de falas sobre a manutenção do teto de gasto como forma de controle das despesas públicas e/ ou nas formas de obtenção de alocação de recursos para a manutenção de auxílios financeiros às populações vulneráveis. Essas incertezas e contradições não são muito bem recebidas pelo mercado e prejudicam as negociações para obtenção do necessário respaldo do Congresso Nacional na obtenção de consenso sobre a recuperação da economia e a mitigação dos efeitos sociais da crise sanitária.

Para o curto prazo, alguns indicativos da atuação governamental nesse sentido podem ser obtidos dos Projetos de Leis das Diretrizes Orçamentárias (BRASIL, 2021a) e Orçamentária Anual (BRASIL, 2021b), nos quais constam as origens das receitas, as 
despesas, metas fiscais e prioridades de governo, além das formas de acesso aos recursos públicos federais em 2021.

As prioridades e as metas físicas da administração pública federal para o próximo exercício, de acordo com a Lei $\mathrm{n}^{\circ} 13.971$, de 27 de dezembro de 2019, que instituiu o Plano Plurianual da União (PPA) para o período de 2020 a 2023, consistem na agenda para a primeira infância e nos investimentos em andamento. São intenções bastante genéricas, cuja ênfase precisa de melhor justificativa, metas físicas e especificação do seu direcionamento.

A Nota Técnica Conjunta ${ }^{\circ} 1 / 2020$, do Congresso Nacional elaborada para orientar a análise, pelos congressistas, das propostas do governo federal para 2021, contidas no PLDO 2021, destaca o artigo $4^{\circ}$ por estabelecer como metas e prioridades a agenda para a primeira infância e os investimentos prioritários definidos no PPA 2020-2023. Avalia que essas argumentações apresentam fragilidades uma vez que a agenda para a primeira infância é imprecisa em relação aos programas e ações orçamentárias que a compõem e não consta nenhuma quantificação do que se pretende. Por outro lado, os investimentos plurianuais prioritários, discriminados no Anexo III do PPA 2020-2023, são limitantes da inclusão de projetos novos no PLOA 2021, enquanto não forem adequadamente atendidos aqueles "em andamento" e contempladas as despesas de "conservação do patrimônio público". A priorização de projetos em andamento visa a minimizar o problema de "obras inacabadas", colaborando para reduzir a ineficiência no gasto público.

Com relação à participação da União na retomada da economia, via aquecimento do mercado e da redução do desemprego, Funcia, Benevides e Ocke (2020) pontuam que o PLDO 2021 assume que a regra do teto de despesas primárias da $\mathrm{EC} \mathrm{n}^{\circ}$ 95/2016 será retomada em 2021, atribuindo às despesas primárias do governo central uma situação de evolução limitada que amordaça a ação 
governamental na retomada do crescimento e do pleno emprego da economia. Dado o cenário conjuntural atual, a expectativa para 2021 e para os anos subsequentes deveria ser de elevação de gastos governamentais para estimular os investimentos privados e para garantir uma renda de subsistência à população.

Com relação ao setor saúde, os indicativos do PLDO 2021 são incompatíveis com as necessidades sanitárias da população e da situação social do país em decorrência da pandemia do novo coronavírus e com um Sistema Único de Saúde (SUS) já subfinanciado. Espera-se a manutenção dos gastos em níveis de 2020, para paralelamente ao atendimento aos casos de COVID-19 remanescentes, viabilizar a realização de consultas de rotinas, cirurgias eletivas e exames laboratoriais e de imagens que foram postergados, gerando um represamento de demanda. No campo do investimento em saúde, necessário se faz a manutenção, substituição e ampliação das instalações e equipamentos de saúde; investimentos em pesquisa; desenvolvimento e produção de insumos, vacinas, medicamentos e equipamentos de proteção individual para os trabalhadores de saúde, inclusive para atender à oferta de máscaras para uso de toda a população, entre outras necessidades. (FUNCIA et al., 2020)

Funcia, Ocke e Moretti (2020) destacam ainda que com o fim da regra do orçamento emergencial de 2020, o Conselho Nacional de Saúde (CNS) estima uma perda de R 35 bilhões em 2021 em relação ao que está autorizado atualmente para a cobertura das despesas do SUS. Esse valor, 22\% dos recursos atualmente alocados para o setor, equivale ao custeio de cinco Programas Mais Médicos ou oito vezes o investimento anual em vacinação. Com relação ao PLOA 2021, observa-se aderência às proposições do PLDO no que diz respeito ao teto de gastos, dessa forma, os valores orçados projetados para 2021 obedeceram ao determinado pela EC $n^{\circ}$ 95/2016 e foram baseados em parâmetros conservadores, contando nesse 
horizonte com déficits persistentes, porém decrescentes. Dessa forma, a proposta do orçamento federal para 2021, encaminhada ao Congresso Nacional restringe os gastos extraordinários para enfrentamento da COVID-19 ao exercício 2020. Toma como parâmetro para a elevação das receitas primárias a implementação das reformas tributária e administrativa, cuja economia poderá responder com ganhos de produtividade.

Considerando que o PLOA é elaborado no ano anterior de sua vigência, o Ministério da Economia elaborou uma projeção da arrecadação das receitas e da maneira como esses valores serão gastos. As projeções realizadas consideraram parâmetros para estimar as receitas de 2021 (PIB, inflação, taxa de juros, taxa de câmbio, salário-mínimo, entre outros). Com base nessas projeções, o PLOA de 2021 indica uma meta de déficit primário de $\mathrm{R} \$ 233,6$ bilhões, resultante da diferença das projeções da Receita Primária Líquida de R \$ 1.292,5 bilhões e da Despesa Primária Líquida de R \$ 1.520,7 bilhões, considerados fatores e ajustes de $\mathrm{R} \$ 5,4$ bilhões.

No PLOA 2021, as despesas primárias, aquelas que resultam em bens e serviços públicos, além dos gastos necessários para a manutenção da estrutura do Estado, foram estimadas em R R R 1.516,8 bilhão. Essas despesas podem ser discricionárias ou obrigatórias. As obrigatórias, aquelas que a União tem a obrigação constitucional ou legal de realizar, foram previstas em $\mathrm{R} \$ 1.420,7$ bilhão. Para as despesas discricionárias, cuja execução depende da avaliação ou escolha do governo acerca da conveniência e da oportunidade, foram previstos R 96,1 bilhões. (BRASIL, 2021a)

Para a saúde, o Poder Executivo propôs R\$ 136,7 bilhões visando à manutenção das determinações constitucionais em 2021. No entanto, o teto condicionado pela EC n ${ }^{\circ}$ 95/2016 é de $\mathrm{R} \$ 123,8$ bilhões. (BRASIL, 2021a) Dessas despesas orçadas, 85\% são obrigatórias, 14 \% discricionárias e 1\% financeiras. A distribuição entre as áreas de atuação em saúde obedeceu aos seguintes percentuais: 
Assistência Hospitalar e Ambulatorial (47\%); Atenção Básica (20\%); Suporte Profilático e Terapêutico (13\%); Administração Geral (7\%); Vigilância Epidemiológica (7\%); e demais áreas 6\% do orçamento cidadão. Na área da saúde, há um descompasso entre o orçado para 2021 e a dotação atualizada para 2020, expandida para atender às necessidades da pandemia do coronavírus. Levando-se em consideração que a crise sanitária não termina no último dia do ano, o CNS apresenta uma situação de 28 de julho de 2020 em que a dotação disponível (LOA 2020 + créditos) foi de R \$ 159,17 bilhões. O piso calculado para 2021, de acordo com a EC n ${ }^{\circ} 95 / 2016$, é de $\mathrm{R} \$ 123,83$ bilhões, o que significa uma perda, em 2021, de R\$ 35,34 em relação ao disponível em 2020. Funcia, Ocke e Moretti (2020) calcularam um piso emergencial de R \$ 168,7 bilhões para o financiamento federal das ações e serviços públicos de saúde em 2021. É oportuno ressaltar que, antes da COVID-19, o financiamento federal da saúde foi impactado negativamente pelas regras da $\mathrm{EC} \mathrm{n}^{\circ} 95 / 2016$, cujas perdas foram estimadas em $\mathrm{R} \$ 22,5$ bilhões. (FUNCIA et al., 2020)

O que esse panorama demonstra, para todos os setores, é uma total incompatibilidade com a realidade da atual crise sanitária ao tentar comprimir despesas crescentes, não apenas com saúde, em um teto fixado pela EC $n^{\circ}$ 95/2016 em época com outra realidade social. Entre as proposições para esse impasse, a equipe econômica do atual governo sugere medidas que aprofundam ainda mais o hiato de cobertura das complexas necessidades socais da população. São proposições que ferem outros direitos, a exemplo do uso dos recursos do Fundo de Manutenção e Desenvolvimento da Educação Básica (Fundeb) para financiar o programa de renda mínima sem nome ainda definido.

Em resumo, em meio à crise sanitária provocada pela COVID-19, economistas de todos os matizes deveriam examinar como a política econômica pode determinar as causas de 
morbimortalidade de uma sociedade. David Stuckler e Sanjay Basu deram uma contribuição importante nesse sentido. No livro, publicado em 2013, intitulado The body economic: Why austerity kills, os autores criticaram, impetuosamente, os efeitos das políticas de austeridade fiscal sobre as condições de vida e saúde das populações. Ora, se antes da pandemia esse quadro já era preocupante, quando assistimos no Brasil à morte de mais de 158 mil pessoas e a existência de mais de 5 milhões de casos de COVID-19, ${ }^{13}$ não deixa de ser chocante constatar o subfinanciamento crônico do SUS, agravado pelo teto do gasto definido pela EC n 95/2016.

Por seu turno, o PLDO de 2021 traz como âncora fiscal o teto de gasto. A meta de resultado primário é prevista na Lei de Responsabilidade Fiscal. Em razão da forte incerteza sobre a recuperação da economia - arrecadação de tributos -, na prática, não haverá meta de resultado primário, que será dada pela diferença entre a despesa, limitada pelo teto, e a arrecadação observada. Ou seja, trata-se de uma meta frouxa, de modo que não deverá haver contingenciamentos caso haja frustração de receita, o que implicará um contingenciamento de despesas.

Outro ponto importante a destacar é a baixa execução dos recursos federais do Ministério da Saúde para o enfrentamento da COVID-19, particularmente no ápice da epidemia no Brasil, como divulgado semanalmente pelo CNS no boletim elaborado pela sua Comissão de Orçamento e Financiamento (Cofin). Ou seja, o atraso de repasse aos estados e municípios tornou muito difícil sua execução, tendo sido proposto projeto de lei para a extensão dos prazos de aplicação dos recursos federais transferidos aos demais entes da Federação para execução dos recursos pelos entes federados. (BRASIL, 2020j) E, por fim, cabe reforçar a extrema importância do piso emergencial de R\$168,7 bilhões para o SUS em

13 Até 20 de outubro de 2020. 


\section{1, como mecanismo de reposição dos valores necessários para manutenção do orçamento da saúde em relação a 2020, conside- rando a inflação do setor e o crescimento da população.}

\section{Referências}

AHMED, F. et al. Why inequality could spread COVID-19. The Lancet Public Health, Oxford, v. 5, n. 5, p. e240, May 2020.

ALTIG, D. et al. Economic uncertainty before and during the COVID-19 pandemic. Journal of Public Economics, Amsterdam, v. 191, p. 104274, 2020.

ALVES, C.; KVANGRAVEN, I. H. Changing the narrative: Economics after Covid-19. Review of Agrarian Studies, [s. I.], v. 10, n. 1, p. 147-163, Jan. 2020.

BALTRUSIS, N.; D'OTTAVIANO, M. C. L. Rich and poor, each one in their place: Socioespatial inequality in São Paulo. Caderno CRH, Salvador, v. 22, n. 55 , p. $135-149,2009$.

BAQAEE, D. et al. Policies for a second wave. Brookings Papers on Economic Activity, Washington, 25 June 2020.

BOHOSLAVSKY, J. P.; RULLI, M. Covid-19, instituciones financieras internacionales y continuidad de las políticas androcéntricas en América Latina. Revista Estudos Feministas, Florianópolis, v. 28, n. 2, p. 1-16, 2020.

BRANDÃO, V. O papel do Estado como garantidor de emprego e renda durante a pandemia do novo Coronavírus Vinicius Brandão. Boletim FINDE, Niterói, n. 1, p. 50-54, maio 2020. Disponível em: https://www.researchgate.net/ profile/Carmem_Feijo2/publication/341255524_Covid_19_e_os_desafios_ao_ desenvolvimento/links/5eb5b8d34585152169c0f160/COVID-19-e-os-desafios-aodesenvolvimento.pdf\#page=52. Acesso em: 25 set. 2020 .

BRASIL. Congresso Nacional. Nota Técnica Conjunta n 1/2020. Brasília, DF, 2020a. Disponível em: https://www.cnmp.mp.br/portal/images/Portarias_ Presidencia_nova_versao/Nota-Tcnica-Conjunta-n-1-2020-Corona-vrus.pdf. Acesso em: 5 out. 2020. 
BRASIL. Congresso Nacional. Projeto de Lei do Congresso Nacional nº 9, de 2020. Dispõe sobre as diretrizes para a elaboração e a execução da Lei Orçamentária de 2021 e dá outras providências. Brasília, DF, 2021a. Disponível em: https:// www.congressonacional.leg.br/materias/materias-orcamentarias/pldo-2021. Acesso em: 7 out. 2020.

BRASIL. Decreto $n^{\circ} 10.305$, de 1 de abril de 2020. Altera o Decreto $n^{\circ} 6.306$, de 14 de dezembro de 2007, que regulamenta o Imposto sobre Operações de Crédito, Câmbio e Seguro ou relativas a Títulos ou Valores Mobiliários. Diário Oficial da União, Brasília, DF, 1 abr. 2020b. Disponível em: http://www.normaslegais.com.br/ legislacao/decreto-10305-2020.htm. Acesso em: 23 set. 2020.

BRASIL. Emenda Constitucional n 95, de 15 de dezembro de 2016. Altera o Ato das Disposições Constitucionais Transitórias, para instituir o Novo Regime Fiscal, e dá outras providências. Diário Oficial da União, Brasília, DF, 15 dez. 2016. Disponível em: http://www.planalto.gov.br/ccivil_03/constituicao/emendas/emc/ emc95.htm. Acesso em: 7 out. 2020.

BRASIL. Lei $n^{\circ}$ 13.971, de 27 de dezembro de 2019. Institui o Plano Plurianual da União para o período de 2020 a 2023. Diário Oficial da União, Brasília, DF, 2019. Disponível em: http://www.planalto.gov.br/ccivil_03/_ato2019-2022/2019/lei/ L13971.htm. Acesso em: 15 de set. de 2020.

BRASIL. Lei $n^{\circ} 13.982$, de 2 de abril de 2020. Altera a Lei $n^{\circ}$ 8.742, de 7 de dezembro de 1993, para dispor sobre parâmetros adicionais de caracterização da situação de vulnerabilidade social para fins de elegibilidade ao benefício de prestação continuada (BPC), e estabelece medidas excepcionais de proteção social a serem adotadas durante o período de enfrentamento da emergência de saúde pública de importância internacional decorrente do coronavírus (Covid-19) responsável pelo surto de 2019, a que se refere a Lei $n^{\circ} 13.979$, de 6 de fevereiro de 2020. Diário Oficial da União, Brasília, DF, 2 abr. 2020c. Disponível em: http:// www.planalto.gov.br/ccivil_03/_ato2019-2022/2020/lei/l13982.htm.

Acesso em: 21 set. 2020. 
BRASIL. Lei $n^{\circ} 14.020$, de 6 de julho DE 2020. Institui o Programa Emergencial de Manutenção do Emprego e da Renda; dispõe sobre medidas complementares para enfrentamento do estado de calamidade pública reconhecido pelo Decreto Legislativo $n^{\circ}$ 6, de 20 de março de 2020, e da emergência de saúde pública de importância internacional decorrente do coronavírus, de que trata a Lei $n^{\circ} 13.979$, de 6 de fevereiro de 2020; altera as Leis n os 8.213, de 24 de julho de 1991, 10.101, de 19 de dezembro de 2000, 12.546, de 14 de dezembro de 2011, 10.865, de 30 de abril de 2004, e 8.177, de $1^{\circ}$ de março de 1991; e dá outras providências. Diário Oficial da União, Brasília, DF, 2020d. Disponível em: http://www.planalto.gov.br/ ccivil_03/_ato2019-2022/2020/Lei/L14020.htm. Acesso em: 20 de set. de 2020.

BRASIL. Medida Provisória n 927, de 22 de março de 2020. Dispõe sobre as medidas trabalhistas para enfrentamento do estado de calamidade pública reconhecido pelo Decreto Legislativo $n^{\circ}$ 6, de 20 de março de 2020, e da emergência de saúde pública de importância internacional decorrente do coronavírus (covid-19), e dá outras providências. Diário Oficial da União, Brasília, DF, 22 mar. 2020e. Disponível em: http://www.planalto.gov. br/ccivil_03/_ato2019-2022/2020/mpv/mpv927.htm\#: :text=MPV\%20 927\&text=Disp\%C3\%B5e\%20sobre\%20as\%20medidas\%20trabalhistas,)\%2C\%20 e\%20d\%C3\%A1\%20outras\%20provid\%C3\%AAncias. Acesso em: 20 set. 2020.

BRASIL. Medida Provisória n 933, de 31 de março de 2020. Suspende, pelo prazo que menciona, o ajuste anual de preços de medicamentos para o ano de 2020. Diário Oficial da União, Brasília, DF, 31 mar. 2020f. Disponível em: http:// www.planalto.gov.br/ccivil_03/_Ato2019-2022/2020/Mpv/mpv933.htm. Acesso em: 23 set. 2020.

BRASIL. Medida Provisória $n^{\circ}$ 936, de $1^{\circ}$ de abril de 2020. Institui o Programa Emergencial de Manutenção do Emprego e da Renda e dispõe sobre medidas trabalhistas complementares para enfrentamento do estado de calamidade pública reconhecido pelo Decreto Legislativo n 6 , de 20 de março de 2020, e da emergência de saúde pública de importância internacional decorrente do coronavírus (covid-19), de que trata a Lei $\mathrm{n}^{\circ}$ 13.979, de 6 de fevereiro de 2020, e dá outras providências. Diário Oficial da União, Brasília, DF, 1 abr. 2020g. Disponível em: http://www.planalto.gov.br/ccivil_03/_ato2019-2022/2020/mpv/ mpv936.htm. Acesso em: 20 set. 2020. 
BRASIL. Medida Provisória n 950, de 8 de abril de 2020. Dispõe sobre medidas temporárias emergenciais destinadas ao setor elétrico para enfrentamento do estado de calamidade pública reconhecido pelo Decreto Legislativo $n^{\circ} 6$, de 20 de março de 2020, e da emergência de saúde pública de importância internacional decorrente da pandemia de coronavírus (covid-19). Diário Oficial da União, Brasília, DF, 8 abr. 2020h. Disponível em: http://www.planalto.gov.br/ccivil_03/_ ato2019-2022/2020/Mpv/mpv950.htm. Acesso em: 23 set. 2020.

BRASIL. Nota informativa: medidas de Combate aos Efeitos Econômicos da COVID-19. Brasília, DF, 17 abr. 2020i. Disponível em: https://www.gov.br/ economia/pt-br/centrais-de-conteudo/publicacoes/notas-informativas/2020/ nota-informativa-medidas-fiscais-coronavirus-final-17_04.pdf/view. Acesso em: 15 set. 2020.

BRASIL. Projeto de Lei do Congresso Nacional $n^{\circ} 28$, de 2020. Proposta do Poder Executivo. Brasília, DF, 2021b. Disponível em: https://www2.camara.leg.br/ orcamento-da-uniao/leis-orcamentarias/loa/2021/tramitacao/proposta-dopoder-executivo/Projeto.html. Acesso em: 7 out. 2020.

BRASIL. Projeto de Lei $n^{\circ} 4078$, de 2020. Dispõe sobre a extensão dos prazos de aplicação dos recursos federais transferidos aos demais entes da Federação com fundamento em atos infralegais quando os recursos forem vinculados à execução de ações de enfrentamento e mitigação dos efeitos sociais adversos da pandemia da covid-19. Brasília, DF, 2020j. Disponível em: https://www25.senado.leg.br/web/ atividade/materias/-/materia/143778. Acesso em: 7 out. 2020.

BUSSO, M.; MESSINA, J. (ed.). The inequality crisis: Latin America and the Caribbean at the Crossroads. [S. I.]: IDB, 2020. Disponível em: https://publications.iadb.org/ publications/english/document/The-Inequality-Crisis-Latin-America-and-theCaribbean-at-the-Crossroads.pdf. Acesso em: 13 out. 2020.

CALMON, T. V. L. As condições objetivas para o enfrentamento ao COVID-19: abismo social brasileiro, o racismo, e as perspectivas de desenvolvimento social como determinantes. Revista NAU Social, Salvador, v. 11, n. 20, p. 131-136, maio/out. 2020.

CÂMARA, S. F. et al. Vulnerabilidade socioeconômica à COVID-19 em municípios do Ceará. Revista de Administração Pública, Rio de Janeiro, v. 54, n. 4, p. 1037-1051, 2020. 
CARVALHO, S. S. de. Os efeitos da pandemia sobre os rendimentos do trabalho e o impacto do auxílio emergencial: os resultados dos microdados da PNAD COVID-19 de julho. Carta de Conjuntura, Brasília, DF, n. 48, p. 1-17, 2020. Disponível em: https://www.ipea.gov.br/portal/images/stories/PDFs/ conjuntura/200826_cc48_resultados_pnda_julho.pdf. Acesso em: 25 set. 2020.

COMISSÃO ECONÔMICA PARA A AMÉRICA LATINA E O CARIBE - CEPAL. Estudio Económico de América Latina y el Caribe 2020: principales condicionantes de las políticas fiscal y monetaria en la era pos pandemia de COVID-19. Santiago de Chile, 2020. Disponível em: https://www.cepal.org/es/publicaciones/46070estudio-economico-america-latina-caribe-2020-principales-condicionantes? Acesso em: 8 out. 2020.

CHADE, J. Bilionários ficam ainda mais ricos no Brasil e no mundo durante a pandemia. UOL, [s. I.], 7 out. 2020. Disponível em: https://noticias.uol.com.br/ colunas/jamil-chade/2020/10/07/pandemia-fez-bilionarios-ficarem-ainda-maisricos-no-brasil-e-no-mundo.htm. Acesso em: 8 out. 2020.

CORREIA, S.; LUCK, S.; VERNER, E. Pandemics Depress the Economy, Public Health Interventions Do Not: Evidence from the 1918 Flu. 5 june 2020.

Disponível em: https://papers.ssrn.com/sol3/papers.cfm?abstract_id=3561560. Acesso em: 8 out. 2020.

COSTA, J. S. M.; REIS, M. C. Uma análise da MP no 936 sobre os rendimentos dos trabalhadores e a renda domiciliar per capita. Brasília, DF: Ipea, maio 2020. (Nota Técnica, v. 71).

FUNCIA, F. R. BENEVIDES, R.; OCKE, C. Boletim CNS/Cofin 2020/04/22/1e2A-B. 2020. Disponível em: http://idisa.org.br/domingueira/domingueira-n-16-abril2020\#a0. Acesso em: 22 out. 2020.

FUNCIA, F. R. et al. Por que o Congresso Nacional não pode permitir a redução dos recursos do SUS para 2021. Jornal GGN, [s. I.], 17 abr. 2020. Disponível em: https:// jornalggn.com.br/a-grande-crise/por-que-o-congresso-nacional-nao-podepermitir-a-reducao-dos-recursos-do-sus-para-2021/. Acesso em: 22 out. 2020.

FUNCIA, F. R.; OCKE, C.; MORETTI, B. "Fanatismo fiscal" está levando Brasil ao caos social; SUS merece mais em 2021. Fanatismo Fiscal e Caos Social. Viomundo, [s. I.], 8 set. 2020. Disponível em: https://www.viomundo.com.br/blogdasaude/ funcia-ocke-e-moretti-fanatismo-fiscal-esta-levando-o-brasil-ao-caos-social.html. Acesso em: 22 out. 2020. 
GUIMÓN, P. FMI prevê contração de 3\% na economia mundial em 2020, a maior desde 1930. El País, Washington, 14 abr. 2020. Disponível em: https://brasil.elpais. com/economia/2020-04-14/fmi-preve-contracao-de-3-na-economia-mundialem-2020-a-maior-desde-1930.html. Acesso em: 8 out. 2020.

INTERNATIONAL LABOUR ORGANIZATION - ILO. ILO Monitor: COVID-19 and the world of work. Second edition Updated estimates and analysis. 7 Abr. 2020.

Disponível em: https://www.ilo.org/wcmsp5/groups/public/---dgreports/--dcomm/documents/briefingnote/wcms_740877.pdf. Acesso em: 21 set. 2020.

KOMATSU, B. K.; MENEZES-FILHO, N. Simulações de Impactos da COVID-19 e da Renda Básica Emergencial sobre o Desemprego, Renda, Pobreza e Desigualdade. Policy Paper, [s. I.], n. 43, p. 1-31, abr. 2020. Disponível em: https://www.insper.edu. br/wp-content/uploads/2020/04/Policy-Paper-v14.pdf. Acesso em: 25 set. 2020.

LABORDE, D. et al. COVID-19 risks to global food security. Science, Washington, v. 369, n. 6503, p. 500-502, 2020.

MAYHEW, K.; ANAND, P. COVID-19 and the UK labour market. Oxford Review of Economic Policy, Oxford, v. 36, n. 1, p. S215-S224, 2020.

MCKEE, M.; STUCKLER, D. If the world fails to protect the economy, COVID-19 will damage health not just now but also in the future. Nature Medicine, New York, v. 26, n. 5 , p. $640-642,2020$.

NASSIF-PIRES, L. et al. Pandemic of inequality. Public Policy Brief, New York, n. 149, 2020.

ONU MUJERES; COMISSÃO ECONÔMICA PARA A AMÉRICA LATINA E O CARIBE CEPAL, N. U. Cuidados na América Latina e no Caribe em tempos de COVID-19: em direção a sistemas integrais para fortalecer a resposta e a recuperação. Santiago de Chile, 2020. Disponível em: https://www.cepal.org/pt-br/publicaciones/45923cuidados-america-latina-caribe-tempos-covid-19-direcao-sistemas-integrais. Acesso em: 20 set. 2020.

PEREIRA, M.; OLIVEIRA, A. Poverty and food insecurity may increase as the threat of COVID-19 spreads. Public Health Nutrition, Oxford, v. 3, p. 17, p. 3236-324, 2020.

PIRES, L. L.; CARVALHO, L.; XAVIER, L. L. COVID-19 e Desigualdade no Brasil. 2020. Disponível em: https://www.researchgate.net/publication/340452851_COVID19_e_ Desigualdade_no_Brasil. Acesso em: 20 set. 2020.

POWER, M. et al. How COVID-19 has exposed inequalities in the UK food system: The case of UK food and poverty. Emerald Open Research, [s. I.], v. 2, p. 11, 2020. 
SANDERS, B. The pandemic is helping the rich get even richer. It's time to tax their obscene wealth. The Guardian, London, 11 Aug. 2020. Disponível em: https://www. theguardian.com/commentisfree/2020/aug/11/the-pandemic-is-helping-the-richget-even-richer-its-time-to-tax-their-obscene-wealth. Acesso em: 20 set. 2020.

SANTOS, F. H. S.; MIRANDA, M. S.; MONTI JUNIOR, B. A importância do contrato de teletrabalho durante a pandemia do COVID-19. Revista Interciência - IMES Catanduva, São Paulo, v. 1, n. 4, p. 1-6, 2020.

SILVA, M. S. Política econômica emergencial orientada para a redução dos impactos da pandemia da COVID-19 no Brasil: medidas fiscais, de provisão de liquidez e de liberação de capital. Texto para Discussão, Brasília, DF, n. 2576, p. 1-2, jul. 2020. Disponível em: http://repositorio.ipea.gov.br/bitstream/11058/10190/1/ td_2576_sumex.pdf. Acesso em: Acesso em: 04 set. 2020.

STUCKLER, D.; BASU, S. The Body Economic: Why Austerity Kills. London: Allen Lane, 2013.

THE WORLD BANK. Perspectivas econômicas globais. Washington, c2021. Disponível em: https://www.worldbank.org/pt/publication/global-economicprospects. Acesso em: 8 out. 2020.

TROVÃO, C. J. B. M. A. Pandemia da COVID-19 e a Desigualdade de Renda no Brasil: Um Olhar Macrorregional para a Proteção Social e os Auxílios Emergenciais. Texto para Discussão, Natal, n. 004, maio 2020. Disponível em: https://www.researchgate.net/profile/Cassiano_Trovao/ publication/341713346_Texto_para_Discussao_004_2020_A_Pandemia_da_COVID19_e_a_Desigualdade_de_Renda_no_Brasil_Um_Olhar_Macrorregional_para_a_ Protecao_Social_e_os_Auxilios_Emergenciais/links/5ed00f9c92851c9c5e65d579/ Texto-para-Discussao-004-2020-A-Pandemia-da-COVID-19-e-a-Desigualdade-deRenda-no-Brasil-Um-Olhar-Macrorregional-para-a-Protecao-Social-e-os-AuxiliosEmergenciais.pdf. Acesso em: 4 set. 2020.

VAN DORN, A.; COONEY, R. E.; SABIN, M. L. COVID-19 exacerbating inequalities in the US. Lancet, London, v. 395, n. 10232, p. 1243-1244, 2020. 